
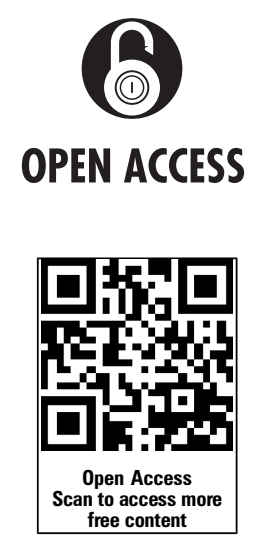

Handling editor Tore K Kvien

- Additional material is published online only. To view please visit the journal online (http://dx.doi.org/10.1136/ annrheumdis-2013-205060).

For numbered affiliations see end of article.

Correspondence to Dr Jonas Eriksson, Department of Medicine (Solna), Clinical Epidemiology Unit (T2),

Karolinska Institutet, Stockholm SE-171 76, Sweden; jonas.eriksson@ki.se

JKE, JAK, PG and MN contributed equally.

\section{Presentation of Results:} Results were presented in abstract form in an oral presentation at the European League Against Rheumatism annual conference in Madrid, 13 June, 2013 (presentation number OP0094; available at http://www.abstracts2view. com/eular/view.php? nu=EULAR13L_OP0094).

Received 12 December 2013 Revised 19 March 2014 Accepted 23 March 2014 Published Online First 15 April 2014

\title{
Cost-effectiveness of infliximab versus conventional combination treatment in methotrexate-refractory early rheumatoid arthritis: 2-year results of the register-enriched randomised controlled SWEFOT trial
}

\author{
Jonas K Eriksson, ${ }^{1}$ Johan A Karlsson, ${ }^{2}$ Johan Bratt, ${ }^{3}$ Ingemar F Petersson, ${ }^{2,4}$ \\ Ronald F van Vollenhoven, ${ }^{5}$ Sofia Ernestam, ${ }^{6}$ Pierre Geborek, ${ }^{2}$ Martin Neovius ${ }^{1}$
}

\section{ABSTRACT}

Objective To estimate the incremental costeffectiveness of infliximab versus conventional combination treatment over 21 months in patients with methotrexate-refractory early rheumatoid arthritis. Methods In this multicentre, two-arm, parallel, randomised, active-controlled, open-label trial, rheumatoid arthritis patients with $<1$ year symptom duration were recruited from 15 rheumatology clinics in Sweden between October 2002 and December 2005. After 3-4 months of methotrexate monotherapy, patients not achieving low disease activity were randomised to addition of infliximab or sulfasalazine

+hydroxychloroquine (conventional treatment group). Costs of drugs, healthcare use, and productivity losses were retrieved from nationwide registers, while EuroQol 5-Dimensions utility was collected quarterly.

Results of 487 patients initially enrolled, 128 and 130 were randomised to infliximab and conventional treatment, respectively. The infliximab group accumulated higher drug and healthcare costs (€27 487 vs $€ 10364$; adjusted mean difference $€ 16956(95 \% \mathrm{Cl} 14647$ to

19 162)), while productivity losses did not differ (€33 804 vs $€ 29$ 220; €3961 (95\% Cl -3986 to $11850))$, resulting in higher societal cost compared to the conventional group (€61 291 vs €39 584; €20 916 (95\% Cl 12800 to 28660$)$ ). Mean accumulated quality-adjusted life-years (QALYS) did not differ (1.10 vs 1.12; adjusted mean difference favouring infliximab treatment $0.01(95 \% \mathrm{Cl}-0.07$ to 0.08$))$. The incremental cost-effectiveness ratios for the infliximab versus conventional treatment strategy were $€ 2404$ 197/ QALY from the societal perspective and $€ 1948$ 919/ QALY from the healthcare perspective.

Conclusions In early, methotrexate-refractory rheumatoid arthritis, a treatment strategy commencing with addition of infliximab, as compared to sulfasalazine +hydroxychloroquine, was not cost-effective over 21 months at willingness to pay levels generally considered acceptable.

Trial registration number: NCT00764725.

\section{INTRODUCTION}

Current guidelines recommend methotrexate as the first-line disease-modifying anti-rheumatic drug (DMARD) in early rheumatoid arthritis (RA), though for many patients methotrexate monotherapy insufficiently controls disease activity. The SWEdish FarmacOTherapy (Swefot) trial is unique among available randomised controlled trials in assessing this common situation by randomly allocating early RA patients with inadequate methotrexate response to addition of a biologic or further conventional DMARDs. Another unique feature is that Swefot was a randomised trial conducted within a clinical quality register, and thereafter enriched through linkage with nationwide health registers for outcome assessment. ${ }^{1}$

As previously reported, addition of the tumour necrosis factor (TNF) inhibitor infliximab resulted in better treatment response at $9,^{2}$ but not 15 or 21 months after randomisation, ${ }^{3}$ as compared with addition of the conventional DMARDs sulfasalazine and hydroxychloroquine (also referred to as triple therapy). Superior radiographic outcome and adherence to treatment were observed in the infliximab group, ${ }^{3}{ }^{4}$ while no differences were detected in quality of life or work loss improvement. ${ }^{4} 5$

Over the last decade, the increasing treatment costs of RA, incurred by the introduction of biologic DMARDs, ${ }^{6}$ have led to a growing interest in economic evaluations to determine whether the increased drug costs will be offset by reduced healthcare use and productivity losses, as well as result in better quality of life. Cost-utility analyses assess the incremental cost-effectiveness ratio, comparing the incremental cost per quality-adjusted life-year (QALY) of alternative interventions. Studies apply a healthcare or societal perspective, the latter including medical costs and other costs to society, such as lost productivity. Two recent reviews summarise available cost-effectiveness studies in RA, ${ }^{7}$ none comparing a biologic versus a conventional treatment strategy in patients with early disease and previous DMARD exposure limited to methotrexate monotherapy.

Here, we present a cost-effectiveness analysis based on a register-enriched randomised trial, comparing the cost per QALY over 21 months of adding infliximab or sulfasalazine and hydroxychloroquine to methotrexate in early RA patients with insufficient response to methotrexate monotherapy. 


\section{METHODS}

The Swefot trial has been described in more detail elsewhere. ${ }^{2}$ Briefly, patients with early RA (age $\geq 18$ year; symptom duration $<1$ year) were recruited from 15 rheumatology units in Sweden between 2002 and 2005. Key inclusion criteria were fulfilment of the 1987 revised American College of Rheumatology criteria, ${ }^{9}$ a disease-activity score based on 28 joint count (DAS28) of $>3.2,{ }^{10}$ no previous DMARD treatment, and no or stably dosed oral glucocorticoid therapy for at least 4 weeks, using at most $10 \mathrm{mg}$ daily prednisolone (or equivalent).

\section{Procedures}

Run-in period: At inclusion, all patients started methotrexate monotherapy, with an initial dose of $10 \mathrm{mg}$ per week increased by $5 \mathrm{mg}$ every 2 weeks to $20 \mathrm{mg}$ weekly.

Randomisation: After a 3-4 months methotrexate run-in period, patients with low disease activity (DAS28 $\leq 3.2$ ) left the trial, while those with a remaining DAS28 $>3.2$ were randomly assigned to addition of either infliximab $(3 \mathrm{mg} / \mathrm{kg}$ bodyweight, rounded up to the nearest $100 \mathrm{mg}$ increment, administered intravenously at weeks $0,2,6$, and every 8 weeks thereafter) or sulfasalazine (1000 mg twice daily; orally) and hydroxychloroquine (400 mg daily; orally; conventional treatment group).

The centralised randomisation process was carried out using a computer-generated random allocation sequence. The statistician who prepared the list had no further role in the study. When a patient at the 3-month visit was judged to be eligible for randomisation, the investigator contacted the central study coordinator by telephone and requested randomisation. We did not use stratification or blocking. Doctors and patients were aware of the treatment allocation (addition of two oral drugs vs one infusion).

Treatment adjustments: Allowed treatment changes have been described previously. ${ }^{2}$ Most importantly, in case of adverse events, sulfasalazine or hydroxychloroquine could be dose-reduced or withdrawn (while continuing the other). Alternatively, both could be replaced by cyclosporin A $(2.5 \mathrm{mg} / \mathrm{kg} / \mathrm{day}$; increase up to $5 \mathrm{mg} /$ $\mathrm{kg} /$ day allowed), while infliximab could be switched to etanercept (50 mg subcutaneously once weekly).

Follow-up: Visits were scheduled at run-in, randomisation, and 3, 6, 9, 15 and 21 months after randomisation. Patients could discontinue the assigned treatment at any time for lack of effectiveness, side-effects, or by own choice. Register-based follow-up continued despite protocol breach, and treatment was thereafter decided by the responsible rheumatologist.

\section{Study outcome}

The primary outcome of the Swefot trial was achievement of a European League Against Rheumatism good treatment response, ${ }^{11}$ and has been reported elsewhere. ${ }^{2}$ The current study analysed cost-effectiveness by calculating the incremental cost-effectiveness ratio ( $€$ per QALY), defined as the between-group difference in accumulated costs divided by the difference in accumulated QALYs.

\section{Perspectives and costs}

The cost-effectiveness analysis was conducted from a healthcare and societal perspective. Costs included antirheumatic drugs, inpatient care (including surgery), non-primary outpatient care (including day surgery), and work loss due to sick leave, and disability pension, ${ }^{5}$ estimated during 21 months of follow-up. Baseline costs, used for adjustment, were defined as accumulated costs during 60 days before randomisation. All costs were converted to 2011 euros ( $€$; exchange rate $€ 1=9.03$ SEK).

Data on inpatient and non-primary outpatient care were retrieved from the National Patient Register kept at the Swedish National Board of Health and Welfare. ${ }^{12}$ Costs were calculated using the diagnostic-related group-coding system, a weighted average of costs per disease group, from 2011 (http://www. socialstyrelsen.se).

Antirheumatic drug use (including biologic and conventional DMARDs, glucocorticoids and non-steroidal anti-inflammatory drugs) was collected from the Swedish Rheumatology Quality register, ${ }^{13}$ in which drug doses and frequencies were recorded during the Swefot trial. Costs were calculated using 2011 drug prices in Sweden (http://www.tlv.se). For intravenous medications, costs proportional to the administered dose was used, not accounting for possible redundant drug material.

Day-level data on work loss were retrieved from the Social Insurance Office. ${ }^{5}$ In the main analysis, the human capital method was used, including all accumulated days of sick leave and disability pension. The impact of using, instead, the frictioncost method was tested in a sensitivity analysis, with a friction period of 6 months for individuals to be replaced. ${ }^{14}$ Productivity losses were estimated as the accumulated days of sick leave and disability pension multiplied with the mean average salary per day, including social fees, in Sweden 2011 (http://www.scb.se).

\section{QALYs}

QALYs are estimated using utility instruments, of which the EuroQol 5-Dimensions (EQ-5D) is commonly applied in costeffectiveness analyses of RA. ${ }^{8}{ }^{15}$ In the Swefot trial, EQ-5D utility was assessed quarterly, enabling calculation of accumulated QALYs (the area under the utility curve plotted against time) during 21 months from randomisation, using the trapezoid method. ${ }^{4}$ In the main analysis, the UK EQ-5D preference set was used to calculate utilities, ${ }^{16}$ while the US tariff was tested in a sensitivity analysis. ${ }^{17}$

\section{Discounting}

National pricing and reimbursement agencies generally recommend discounting of costs and effects at 3\% annually. Due to our short follow-up, with only 9 months considered for discounting, data are presented undiscounted.

\section{Statistical analysis}

The Swefot trial was designed to detect a $15 \%$ difference in treatment response according to the European League Against Rheumatism good criteria with a statistical power of $90 \%$ $(\alpha=0.05)$, but closed after enrolment of 487 patients (statistical power $75 \%(\alpha=0.05))$, mainly due to slower recruitment than anticipated. After the run-in phase, 128 patients were randomised to infliximab and 130 to conventional treatment.

All randomised patients were analysed according to the intention-to-treat principle, including observed costs and effects during the full 21 months follow-up irrespective of protocol breach. Incremental cost-effectiveness ratios were estimated in a seemingly unrelated regression model, ${ }^{18}$ adjusting for age, sex, EQ-5D, DAS28 and health assessment questionnaire (HAQ) scores at randomisation, and accumulated costs during 60 days before randomisation. Missing HAQ scores at randomisation $(n=6)$ were imputed by a linear regression model with age, sex and DAS28. As previously described, missing utility data were imputed using a linear regression model at randomisation $(n=34)$, and at later time points by linear interpolation or, in the absence of future measurements, by last observation carried 
forward. ${ }^{4}$ All analyses (main, and sensitivity analyses) were also conducted unadjusted.

To estimate the uncertainty around the incremental costs, effects, and cost-effectiveness ratios, non-parametric bootstrapping with 1000 iterations was used. ${ }^{19}$ Cost and effect differences in the bootstrap samples approached a normal distribution despite skewed cost and effect distributions (see online supplementary figure S1). By applying different ceiling ratios for willingness to pay per QALY to these bootstrap samples, we computed the probability of cost-effectiveness at different willingness-to-pay thresholds, and presented results in cost-effectiveness acceptability curves. ${ }^{20}$

CIs for between-group differences in cost and QALYs were estimated using non-parametric bootstrapping. ${ }^{19}$ Data were analysed using SAS (V.9.2) and STATA (V.11.0).

\section{RESULTS}

\section{Patient characteristics}

A total of 493 patients were screened from October 2002, to December 2005, with 487 subjects enrolled in the study (see online supplementary figure S2). ${ }^{2}$ Of the 258 patients with DAS28>3.2 after the run-in period, 128 were randomised to infliximab and 130 to conventional treatment. Characteristics at randomisation were similar between the treatment groups (table 1).

\section{Costs}

Drug and healthcare use: Due to the high cost of infliximab, the mean total drug cost was higher in the infliximab than the conventional treatment group ( $€ 19215$ vs $€ 4710$; adjusted mean difference $€ 14280$; 95\% CI 12269 to 16101 ; table 2 and online supplementary figure S3). Furthermore, infliximab was administered at the hospital, and patients in the infliximab group had more rheumatologist visits and borderline more inpatient days, resulting in higher healthcare costs than the conventional treatment group ( $€ 8272$ vs $€ 5653$; adjusted mean difference $€ 2676$; $95 \%$ CI 1425 to 4058 ).

Work loss: No between-group difference in productivity losses was detected using the human capital method comparing the infliximab and conventional treatment group ( $€ 33804$ vs $€ 29220$; adjusted mean difference $€ 3961$; $95 \%$ CI -3986 to 11850 ).

Total costs: Total costs were higher in the infliximab than the conventional treatment group from the healthcare (€27 487 vs $€ 10$ 364; adjusted mean difference $€ 16$ 956; 95\% CI 14647 to 19162 ) and societal perspective (€61 291 vs $€ 39584$; adjusted mean difference $€ 20916$; 95\% CI 12800 to 28660 ).

\section{Utility and QALYs}

Using the UK EQ-5D preference set, the mean (SD) utility at 21 months was $0.64(0.28)$ in the infliximab and $0.68(0.25)$ in the conventional treatment arm. ${ }^{4}$ Mean accumulated QALYs were 1.10 in the infliximab and 1.12 in the conventional treatment group (adjusted mean difference favouring infliximab treatment $0.01 ; 95 \% \mathrm{CI}-0.07$ to 0.08 ; table 2 ).

\section{Incremental cost-effectiveness ratios}

From the societal perspective, the incremental cost-effectiveness ratio for the infliximab, as compared to the conventional treatment was $€ 2404197$ per QALY (table 3). From the healthcare perspective the cost was $€ 1948919$ per QALY (table 3). The variation in incremental cost was lower when only including healthcare costs (figure 1).

No bootstrap samples were cost-saving from either the societal or the healthcare perspective (figure 1). With increasing willingness to pay per QALY, the probability of infliximab treatment

\begin{tabular}{|c|c|c|}
\hline Variable & $\begin{array}{l}\text { Infliximab } \\
\text { treatment } \\
(n=128)\end{array}$ & $\begin{array}{l}\text { Conventional } \\
\text { treatment } \\
(n=130)\end{array}$ \\
\hline Women, n (\%) & $97(76)$ & $101(78)$ \\
\hline Rheumatoid factor positive (\%) & $88(69)$ & $85(65)$ \\
\hline Age (years), mean (SD) & $51.9(13.2)$ & $53.7(14.0)$ \\
\hline Symptom duration (months), mean (SD) & $10.1(3.4)$ & $10.1(3.5)$ \\
\hline DAS28, mean (SD) & $4.9(1.0)$ & $4.8(1.0)$ \\
\hline $\mathrm{HAQ}^{*}$, mean $(\mathrm{SD})$ & $0.9(0.5)$ & $1.0(0.6)$ \\
\hline \multicolumn{3}{|l|}{ EQ-5D utility—UK preference set ${ }^{\dagger}$} \\
\hline Mean (SD) & $0.51(0.29)$ & $0.55(0.27)$ \\
\hline Median (25th-75th) & $0.62(0.29-0.73)$ & $0.62(0.52-0.73)$ \\
\hline Minimum-maximum & -0.18 to 1.00 & -0.24 to 1.00 \\
\hline \multicolumn{3}{|l|}{ EQ-5D utility-US preference sett } \\
\hline Mean (SD) & $0.65(0.19)$ & $0.67(0.18)$ \\
\hline Median (25th-75th) & $0.74(0.53-0.80)$ & $0.71(0.60-0.81)$ \\
\hline Minimum-maximum & $0.20-1.00$ & $0.17-1.00$ \\
\hline \multicolumn{3}{|l|}{ Education, $\mathrm{n}(\%)$} \\
\hline$\leq 9$ years & $19(15)$ & $26(20)$ \\
\hline $10-12$ years & $71(55)$ & $63(48)$ \\
\hline$>12$ years & $30(23)$ & $30(23)$ \\
\hline missing & $8(6)$ & $11(8)$ \\
\hline Smoking $\neq, \mathrm{n}(\%)$ & $33(26)$ & $30(23)$ \\
\hline \multicolumn{3}{|l|}{$\begin{array}{l}\text { Accumulated resource use (60 days } \\
\text { before randomisation) }\end{array}$} \\
\hline Drug cost $(€)$, mean (SD) & $23(7.9)$ & $22(8.4)$ \\
\hline \multicolumn{3}{|l|}{ Healthcare use, mean (SD) } \\
\hline Non-primary outpatient care visits & $2.9(2.0)$ & $2.6(1.9)$ \\
\hline Day surgery visits & $0.1(0.0)$ & $0.1(0.0)$ \\
\hline Inpatient days & $0.4(2.4)$ & $0.2(2.0)$ \\
\hline \multicolumn{3}{|l|}{ Work loss } \\
\hline Sick leave days, mean (SD) & $8.7(18.1)$ & $9.6(19.5)$ \\
\hline Disability pension days, mean (SD) & $2.9(11.1)$ & $4.8(15.1)$ \\
\hline Total days, mean (SD) & $11.6(20.2)$ & $14.4(22.7)$ \\
\hline
\end{tabular}

being cost-effective compared to conventional therapy increased slowly, and was $0 \%$ at $€ 50000$ per QALY from both perspectives, and 38\% from the societal and 41\% from the healthcare perspective at $€ 1000000$ per QALY (table 3 and figure 2).

\section{Sensitivity analysis \\ Costs}

Using the friction cost method for valuation of productivity losses, the infliximab group had borderline higher productivity losses (€14 597 vs $€ 12018$; adjusted mean difference $€ 2134$; $95 \%$ CI -284 to 4535 ), and (as with the human capital method) higher total costs ( $€ 42084$ vs $€ 22382$; adjusted mean difference $€ 19090$; 95\% CI 15564 to 22252 ; table 2) than the conventional treatment group.

\section{QALYS}

Mean accumulated QALYs using the US EQ-5D preference set were 1.27 in the infliximab and 1.28 in the conventional 
Table 2 Mean accumulated costs and quality-adjusted life-years (QALYs) over 21 months of follow-up

\begin{tabular}{|c|c|c|c|c|c|}
\hline \multirow[b]{2}{*}{ Cost component } & \multicolumn{2}{|c|}{ Infliximab treatment } & \multicolumn{2}{|c|}{ Conventional treatment } & \multirow[b]{2}{*}{ Adjusted difference $(95 \% \mathrm{CI})$} \\
\hline & Resource use* & Mean cost (SD) & Resource use* & Mean cost (SD) & \\
\hline \multicolumn{6}{|l|}{ Drug use, $\%$ of patients } \\
\hline \multicolumn{6}{|l|}{ Biologics } \\
\hline Infliximab & $95 \%$ & $€ 16870$ (8272) & $8 \%$ & $€ 1080$ (3831) & $€ 15729$ (14 065 to 17178$)$ \\
\hline Etanercept & $13 \%$ & $€ 1901$ (5595) & $16 \%$ & $€ 2281$ (5854) & $-€ 525$ (-1792 to 876$)$ \\
\hline Adalimumab & $2 \%$ & $€ 229$ (1779) & $5 \%$ & $€ 659$ (3144) & $-€ 462(-1180$ to 107$)$ \\
\hline Rituximab & $0 \%$ & 0 & $1 \%$ & $€ 44(503)$ & $-€ 54(-102$ to -39$)$ \\
\hline \multicolumn{6}{|l|}{ Conventional DMARDs } \\
\hline Methotrexate & $100 \%$ & $€ 105$ (34) & $100 \%$ & $€ 113(25)$ & $-€ 8(-15$ to 0$)$ \\
\hline Sulfasalazine & $7 \%$ & $€ 12(53)$ & $96 \%$ & $€ 206$ (139) & $-€ 192(-216$ to -166$)$ \\
\hline Hydroxychloroquine & $5 \%$ & $€ 3(14)$ & $89 \%$ & $€ 78$ (59) & $-€ 74(-85$ to -65$)$ \\
\hline Ciclosporin A & $1 \%$ & $€ 18(207)$ & $9 \%$ & $€ 162$ (682) & $-€ 123(-254$ to -38$)$ \\
\hline Azathioprin & $1 \%$ & $€ 2(22)$ & $1 \%$ & $€ 1(8)$ & $€ 1(-2$ to 9$)$ \\
\hline Leflunomide & $1 \%$ & $€ 3(34)$ & $3 \%$ & $€ 6$ (36) & $-€ 2(-9$ to 10$)$ \\
\hline Chloroquine phosphate & $0 \%$ & 0 & $5 \%$ & $€ 8(43)$ & $-€ 9(-21$ to -3$)$ \\
\hline \multicolumn{6}{|l|}{ Other } \\
\hline Glucocorticoids & $16 \%$ & $€ 6(18)$ & $22 \%$ & $€ 9(20)$ & $-€ 3(-7$ to 2$)$ \\
\hline NSAIDs & $77 \%$ & $€ 65(60)$ & $68 \%$ & $€ 61(62)$ & $€ 2(-13$ to 16$)$ \\
\hline Total drug use & $100 \%$ & $€ 19215$ (7940) & $100 \%$ & $€ 4710$ (7477) & $€ 14280$ (12 269 to 16101$)$ \\
\hline \multicolumn{6}{|l|}{ Healthcare use } \\
\hline Non-primary outpatient care visits & $20(12)$ & $€ 6151(4070)$ & $16(10)$ & $€ 4372(2625)$ & $€ 1749$ (924 to 2672) \\
\hline Rheumatologist & $19(12)$ & $€ 5687$ (3882) & $15(9)$ & $€ 3823$ (2368) & $€ 1813$ (1037 to 2654) \\
\hline Other specialists & $1.5(1.9)$ & $€ 463(690)$ & $1.7(2.3)$ & $€ 548(801)$ & $-€ 64(-249$ to 116$)$ \\
\hline Day surgery procedures & $0.9(2.1)$ & $€ 394$ (866) & $0.9(1.5)$ & $€ 319$ (495) & $€ 77$ (-73 to 271$)$ \\
\hline Hospital admission days & $2.8(7.5)$ & $€ 1726(4211)$ & $1.1(3.5)$ & $€ 961$ (3070) & $€ 850$ (-42 to 1742$)$ \\
\hline Hip/knee prosthesis procedures, n patients & $4(3 \%)$ & $€ 258$ (1446) & $2(2 \%)$ & $€ 127$ (1023) & $€ 170$ (-127 to 499$)$ \\
\hline Total healthcare use & & $€ 8272$ (6288) & & $€ 5653(4233)$ & $€ 2676$ (1425 to 4058$)$ \\
\hline Healthcare perspective costs & & $€ 27487(10$ 101) & & $€ 10364$ (9214) & $€ 16956$ (14 647 to 19162$)$ \\
\hline \multicolumn{6}{|l|}{ Work loss } \\
\hline \multicolumn{6}{|l|}{ Human capital method } \\
\hline Sick leave days & $194(223)$ & $€ 26954$ (30 914) & $144(200)$ & $€ 20027(27716)$ & $€ 4876$ (-1443 to 11373$)$ \\
\hline Disability pension days & 49 (138) & $€ 6849$ (19 104) & $66(165)$ & $€ 9192$ (22 937) & $-€ 915$ (-5338 to 4144$)$ \\
\hline Total work loss days & $244(246)$ & $€ 33804(34115)$ & $211(251)$ & $€ 29220(34764)$ & $€ 3961$ (-3986 to 11850$)$ \\
\hline \multicolumn{6}{|l|}{ Friction cost method } \\
\hline Sick leave days & 87 (76) & $€ 12093$ (10 552) & $64(77)$ & $€ 8935$ (10 715) & $€ 2246$ ( -79 to 4546$)$ \\
\hline Disability pension days & $18(46)$ & $€ 2504$ (6333) & $22(52)$ & $€ 3083(7185)$ & $-€ 112$ (-1637 to 1382$)$ \\
\hline Total work loss days & $105(80)$ & $€ 14597$ (11 098) & 87 (86) & $€ 12018$ (11 972) & $€ 2134$ ( -284 to 4535$)$ \\
\hline \multicolumn{6}{|l|}{ Total societal costs } \\
\hline Human capital method & & $€ 61291$ (36 201) & & $€ 39584(38$ 052) & $€ 20916$ (12 800 to 28660$)$ \\
\hline Friction cost method & & $€ 42084$ (15 112) & & $€ 22382$ (17 118) & $€ 19090$ (15 564 to 22252$)$ \\
\hline \multicolumn{6}{|l|}{ Accumulated QALYs } \\
\hline UK EQ-5D & $1.10(0.40)$ & & $1.12(0.39)$ & & $0.01(-0.07$ to 0.08$)$ \\
\hline US EQ-5D & $1.27(0.27)$ & & $1.28(0.27)$ & & $0.01(-0.05$ to 0.06$)$ \\
\hline
\end{tabular}

treatment group (adjusted mean difference favouring infliximab treatment $0.01 ; 95 \% \mathrm{CI}-0.05$ to 0.06 ; table 2 ).

\section{Incremental cost-effectiveness ratios}

Using the friction cost method for valuation of productivity losses, the adjusted incremental cost was similar to that found by the human capital method, resulting in a similar incremental cost-effectiveness ratio as in the main analysis (tables 2 and 3).

Applying the US, rather than the UK, EQ-5D tariff, the adjusted incremental effect between the treatment groups decreased, resulting in higher incremental cost-effectiveness ratios from the healthcare ( $€ 3183050$ per QALY) and societal perspective (€3 926628 per QALY), as compared to the main analysis.

\section{Unadjusted analysis}

Unadjusted analyses resulted in mean between-group cost differences similar to those found in the adjusted assessments. The point estimate for the mean effect difference was negative in all unadjusted analyses, resulting in a low probability of infliximab treatment being cost-effective (see online supplementary figures S4 and S5, and table S1). 
Clinical and epidemiological research

Table 3 Incremental costs, effects and cost-effectiveness ratios of the infliximab versus the conventional treatment strategy

\begin{tabular}{|c|c|c|c|c|c|c|c|}
\hline \multirow[b]{2}{*}{ Perspective/method } & \multirow[b]{2}{*}{$\mathbf{n}$} & \multirow{2}{*}{$\begin{array}{l}\text { Incremental } \\
\text { cost }(€)\end{array}$} & \multirow{2}{*}{$\begin{array}{l}\text { Incremental } \\
\text { effect (QALY) }\end{array}$} & \multirow{2}{*}{$\begin{array}{l}\text { ICER } \\
\text { (€ per QALY) }\end{array}$} & \multicolumn{3}{|c|}{$\%$ Cost-effective at willingness-to-pay per QALY } \\
\hline & & & & & $€ 50000(\%)$ & $€ 100000(\%)$ & $€ 1000000(\%)$ \\
\hline \multicolumn{8}{|l|}{ Societal perspective } \\
\hline Overall (main analysis) & 258 & 20916 & 0.009 & 2404197 & 0 & 0 & 38 \\
\hline \multicolumn{8}{|l|}{ Sensitivity analysis } \\
\hline Friction cost method & 258 & 19090 & 0.009 & 2194250 & 0 & 0 & 39 \\
\hline US EQ-5D tariff & 258 & 20916 & 0.005 & 3926628 & 0 & 0 & 28 \\
\hline \multicolumn{8}{|l|}{ Healthcare perspective } \\
\hline Overall (main analysis) & 258 & 16956 & 0.009 & 1948919 & 0 & 0 & 41 \\
\hline \multicolumn{8}{|l|}{ Sensitivity analysis } \\
\hline US EQ-5D tariff & 258 & 16956 & 0.005 & 3183050 & 0 & 0 & 32 \\
\hline
\end{tabular}

\section{DISCUSSION}

\section{Main findings}

In this register-enriched randomised controlled trial of early, methotrexate-refractory RA, the addition of infliximab, as compared to sulfasalazine and hydroxychloroquine, resulted in higher drug and healthcare costs, while no differences were detected in productivity losses or QALYs over 21 months. Irrespective of study perspective, compared to the conventional alternative, the infliximab strategy was not found to be costeffective at willingness-to-pay levels generally considered acceptable (US\$50 000-100000 or $£ 20000-30000$ per QALY). ${ }^{21} 22$

This finding is in line with the similar disease-activity improvements observed in both treatment groups at 21 months. ${ }^{3}$ While the superior radiographic results and drug adherence in the infliximab group apparently had little impact on costs and utilities over 2 years, it can currently only be speculated whether such differences could lead to differential physical function or pain in the respective treatment arms and thereby alter the health economic conclusions in the longer term.

\section{Previous research}

Few randomised, controlled trials of RA have presented costeffectiveness results based on directly observed costs and quality of life, ${ }^{23}{ }^{24}$ none addressing methotrexate-refractory early disease. The BeSt trial found initial combination of methotrexate and infliximab in early RA to result in more QALYs and reduced productivity losses, as compared to a strategy commencing with methotrexate, sulfasalazine and prednisone, ${ }^{23}$ though
Figure 1 Bootstrapped incremental cost-effectiveness ratio plots by societal and healthcare perspective for the infliximab versus the conventional treatment strategy.

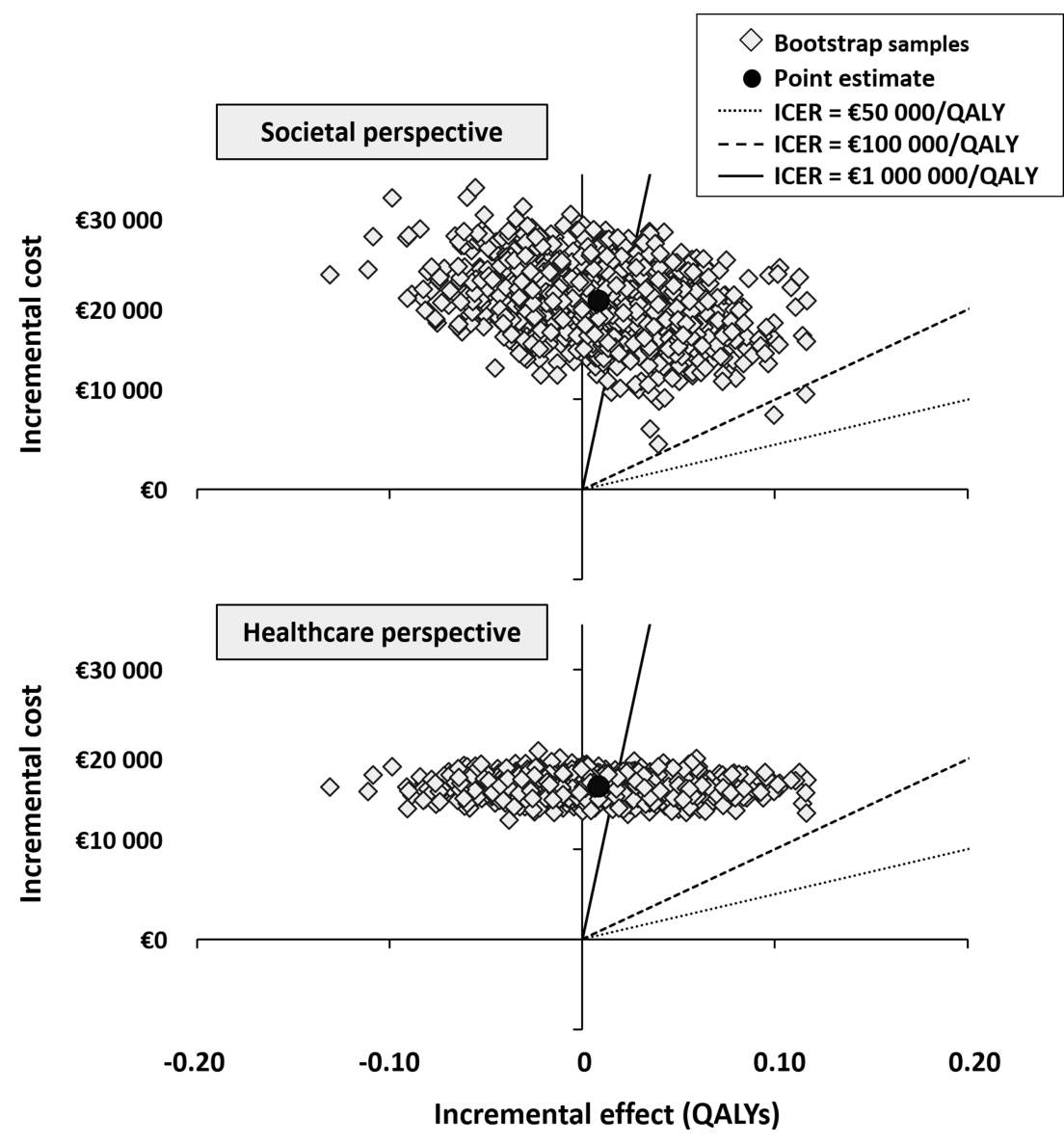




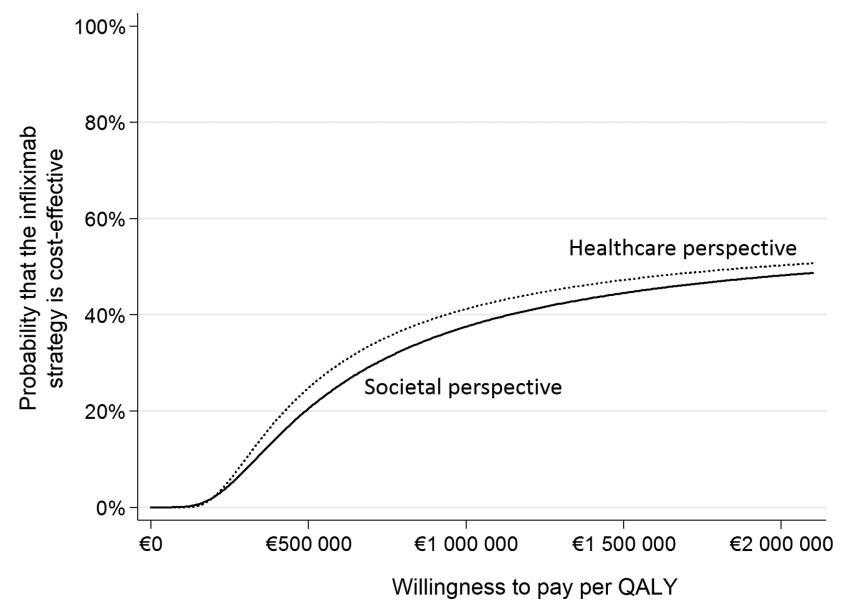

Figure 2 Cost-effectiveness acceptability curves by societal and healthcare perspective for the infliximab versus the conventional treatment strategy.

criticism has been raised for the failure to adjust for baseline productivity. ${ }^{25}$ Differences between the treatment groups evened out after 2 years. ${ }^{24}$ None of the BeSt strategies started with triple therapy, frequent treatment adjustments were allowed, and patients had not previously failed methotrexate, making comparisons with our results difficult. The potential of the Swefot trial to detect differential effects on work loss or utility occurring early after initiation of combination therapy may have been decreased by the improvements seen already during the methotrexate run-in period. ${ }^{4}$

A review of the modelling literature by Schoels et $a l^{7}$ report that TNF inhibitors appear cost-effective after failure with conventional DMARDs, while van der Velde $e t a l^{8}$ conclude that the most cost-effective approach in early RA appears to be to start with a sequence of conventional DMARDs, adding a biologic in case of continued non-response, but doing so before late stages of disease are reached. Either way, the available modelling results are principally based on studies of patients with established RA, and previous exposure to at least two traditional DMARDs, TNF inhibitors added to methotrexate are often compared with continued methotrexate monotherapy, and no available costeffectiveness analyses use triple therapy as comparator. ${ }^{78}$

Combining data from various sources to estimate costeffectiveness over extended time horizons, modelling studies inevitably require a large number of assumptions, ${ }^{26}$ and comparisons to our trial-based results are hampered by the great methodological differences. Apart from the higher drug costs of the infliximab group, our high incremental cost-effectiveness ratio was largely driven by the absence of a between-group difference in QALYs, while cost reductions were also not observed in healthcare use or productivity-all variables that modelling studies often derive indirectly from other clinical parameters such as the HAQ score. ${ }^{8} 26$

The recent TEAR trial compared methotrexate plus etanercept to triple therapy in early RA, reporting similar clinical outcomes and small radiographic differences after 2 years, whether the strategies were used as first-line treatment or following inadequate methotrexate response (as in our study). ${ }^{27}$ Likewise, similar radiographic and clinical outcomes between treatment arms were found after 5 years of follow-up in the NEO-RACo trial, where early RA patients were randomised to receive either initial infliximab or placebo infusions in addition to combination DMARDs. ${ }^{28}$ Furthermore, in patients with established RA and active disease despite methotrexate therapy, triple therapy was recently reported to be non-inferior to methotrexate plus etanercept after 48 weeks regarding reduction of disease activity and radiographic progression. ${ }^{29}$ Although no health economic analyses have been presented based on these trials, it stands to reason that the results would strongly favour conventional therapy.

While we believe our overall findings to be generalisable, the detailed cost results may not be transferable to non-Swedish settings due to the different healthcare and social insurance systems in different countries. Nonetheless, drug and healthcare costs were comparable to those of the BeSt trial, while our register-assessed productivity loss estimates were higher.

\section{Implications}

Based on the 2-year Swefot results, in early, methotrexaterefractory RA, an attempt with conventional triple therapy appears reasonable from a clinical and economic viewpoint before starting infliximab treatment. Larger studies may, however, be needed to confirm our finding.

\section{Strengths}

We addressed a central question of early RA-whether, in the face of insufficient methotrexate response, the addition of a costly anti-TNF agent offers good value for money, as compared to adding further conventional DMARDs.

Data on healthcare use and work loss were retrieved via linkage to national registers, avoiding non-response and recall bias associated with capturing costs by questionnaires. Combined with quality of life and drug use data, this enabled a cost-effectiveness study based solely on direct observations, something not previously available for the treatments studied, and to the best of our knowledge representing the first costeffectiveness analysis of a register-enriched randomised controlled trial.

As seen in table 2, following protocol breach, patients in the conventional arm often received biologic therapy, thus decreasing between-group drug cost differences. To reflect reality, we analysed costs and utilities accumulated during the full 21 months follow-up in all patients by the intention-to-treat principle, thereby comparing two treatment strategies, commencing with addition of either infliximab or further conventional DMARDs upon methotrexate failure.

\section{Limitations}

The open-label design is a limitation of the Swefot trial, as discussed previously. ${ }^{2} 3$ Moreover, the relatively short time horizon, the limited study sample totalling 258 randomised individuals, and powering of the trial to detect a between-group difference in clinical response, and not in costs or QALYs, all entail risks of type two error. However, rather than diverging, quality of life and work loss both followed similar trajectories in the two study groups, ${ }^{4}$ while the higher drug costs in the infliximab arm were considerable.

We did not include costs of primary care, community care and transportation, informal care, patients' out of pocket expenses, or loss of unpaid work and leisure time. In a Swedish survey from 2002, these parameters (loss of unpaid work not included) accounted for $16 \%$ of total societal costs in a cohort of patients with established RA of whom 14\% used biologics. ${ }^{30}$ Based on this and on the absence of a between-group difference in QALYs, potential cost differences in these items would be unlikely to change the study conclusion. 
The intravenous infliximab administration may partly explain the higher healthcare use in the infliximab group. Apart from infusion logistics, the frequent visits could potentially also generate more medical interventions in general. Again, however, in the absence of a QALY difference, and with the large drug cost difference, exclusion of such preparation-driven expenses would only have minor impact on the present results.

Future potential price decreases for infliximab may be anticipated to change the cost-effectiveness outcome. In our analysis, however, even ascribing the same price to both treatment strategies would not produce incremental cost-effectiveness ratios below generally accepted willingness-to-pay levels, due to the lack of a difference in effect and the higher healthcare use in the infliximab group (table 2).

\section{Conclusions}

In patients with methotrexate-refractory early RA, a treatment strategy commencing with addition of infliximab, as compared with sulfasalazine and hydroxychloroquine, was associated with similar effects but higher costs over 21 months. Less radiographic progression was, however, observed with the infliximab strategy, calling for future studies to assess cost-effectiveness in the longer term.

\section{Author affiliations \\ ${ }^{1}$ Clinical Epidemiology Unit, Department of Medicine, Karolinska Institutet, Stockholm, Sweden \\ ${ }^{2}$ Section of Rheumatology, Department of Clinical Sciences Lund, Lund University, Lund, Sweden \\ ${ }^{3}$ Rheumatology Unit, Department of Medicine, Karolinska Institutet, Stockholm, Sweden \\ ${ }^{4}$ Section of Orthopedics, Department of Clinical Sciences Lund, Lund University, Lund, Sweden \\ ${ }^{5}$ Department of Medicine, ClinTRID, Karolinska Institutet, Stockholm, Sweden ${ }^{6}$ Department of Learning, Informatics and Medical Education (LIME), Karolinska Institutet, Stockholm, Sweden}

Acknowledgements We are indebted to all patients, colleagues and staff who made the Swefot trial possible.

Contributors JKE, JAK and MN had full access to all of the data in the study and take responsibility for the accuracy of the data analysis. Trial design: JB, SE, PG, IFP, RFVV. Recruitment of patients: JB, SE, PG, IFP, RFVV. Inclusion and follow-up visits: $J B, S E, P G$, IFP, RFVV. Quality control of data: JB, JKE, SE, PG, JAK, MN, RFVV. Analysis and interpretation of data: JKE, JAK, MN. Drafting of the manuscript: JKE, $J A K, M N$. Critical revision of the manuscript for important intellectual content: JB, JKE, SE, PG, JAK, MN, IFP, RFvV. Study supervision: JB, SE, PG, IFP, RFvV.

Funding The study was funded by the Swedish Rheumatism Association, Stockholm County, and Schering-Plough/Merck Sharp and Dohme. The funding sources had no role in the study design; in the collection, analysis, and interpretation of data; in the writing of the report; or in the decision to submit the paper for publication. Researchers were independent from the funders and sponsors of the study.

Competing interests RFvV has received research support and honoraria from Abbott, GSK/HGS, MSD, Pfizer, Roche and UCB Pharma. MN reported participating in advisory boards for Pfizer (rheumatology) and Abbott (non-rheumatology; unrelated to the current work); participating in research projects fully or partly funded by Schering-Plough, Astra Zeneca, Novo Nordisk, Pfizer, and Roche (unrelated to the current work); and serving as an external consultant (unrelated to rheumatology since 2008) to Pfizer, Sanofi-Aventis, Roche and Abbott. Remaining authors declare no conflict of interest.

Ethics approval The Swefot study was approved by regional ethics committees of all participating units. All participants gave written informed consent before inclusion. The Swefot trial is registered in the WHO database at the Karolinska Hospital, number CT20080004, and clinicaltrials.gov Identifier: NCT00764725.

Provenance and peer review Not commissioned; externally peer reviewed.

Open Access This is an Open Access article distributed in accordance with the Creative Commons Attribution Non Commercial (CC BY-NC 3.0) license, which permits others to distribute, remix, adapt, build upon this work non-commercially, and license their derivative works on different terms, provided the original work is properly cited and the use is non-commercial. See: http://creativecommons.org/ licenses/by-nc/3.0/

\section{REFERENCES}

1 Lauer MS, D'Agostino RB Sr. The randomized registry trial—the next disruptive technology in clinical research? N Engl J Med 2013;369:1579-81.

2 van Vollenhoven RF, Ernestam S, Geborek P, et al. Addition of infliximab compared with addition of sulfasalazine and hydroxychloroquine to methotrexate in patients with early rheumatoid arthritis (Swefot trial): 1-year results of a randomised trial. Lancet 2009;374:459-66.

3 van Vollenhoven RF, Geborek P, Forslind K, et al. Conventional combination treatment versus biological treatment in methotrexate-refractory early rheumatoid arthritis: 2 year follow-up of the randomised, non-blinded, parallel-group Swefot trial. Lancet 2012;379:1712-20.

4 Karlsson JA, Neovius M, Nilsson JA, et al. Addition of infliximab compared with addition of sulfasalazine and hydroxychloroquine to methotrexate in early rheumatoid arthritis: 2-year quality-of-life results of the randomised, controlled, SWEFOT trial. Ann Rheum Dis 2013;72:1927-33.

5 Eriksson JK, Neovius M, Bratt J, et al. Biological vs. conventional combination treatment and work loss in early rheumatoid arthritis: a randomized trial. JAMA Intern Med 2013;173:1407-14.

6 Neovius M, Sundstrom A, Simard J, et al. Small-area variations in sales of TNF inhibitors in Sweden between 2000 and 2009. Scand J Rheumatol 2011;40:8-15.

7 Schoels M, Wong J, Scott DL, et al. Economic aspects of treatment options in rheumatoid arthritis: a systematic literature review informing the EULAR recommendations for the management of rheumatoid arthritis. Ann Rheum Dis 2010;69:995-1003.

8 van der Velde G, Pham B, Machado M, et al. Cost-effectiveness of biologic response modifiers compared to disease-modifying antirheumatic drugs for rheumatoid arthritis: a systematic review. Arthritis Care Res (Hoboken) 2011;63:65-78

9 Arnett FC, Edworthy SM, Bloch DA, et al. The American Rheumatism Association 1987 revised criteria for the classification of rheumatoid arthritis. Arthritis Rheum 1988;31:315-24

10 Prevoo ML, van't Hof MA, Kuper $\mathrm{HH}$, et al. Modified disease activity scores that include twenty-eight-joint counts. Development and validation in a prospective longitudinal study of patients with rheumatoid arthritis. Arthritis Rheum 1995;38:44-8.

11 van Gestel AM, Prevoo ML, van't Hof MA, et al. Development and validation of the European League Against Rheumatism response criteria for rheumatoid arthritis. Comparison with the preliminary American College of Rheumatology and the World Health Organization/International League Against Rheumatism Criteria. Arthritis Rheum 1996;39:34-40.

12 Ludvigsson JF, Andersson E, Ekbom A, et al. External review and validation of the Swedish national inpatient register. BMC Public Health 2011;11:450.

13 Askling J, Fored CM, Geborek P, et al. Swedish registers to examine drug safety and clinical issues in RA. Ann Rheum Dis 2006;65:707-12.

14 Koopmanschap MA, Rutten FF, van Ineveld BM, et al. The friction cost method for measuring indirect costs of disease. J Health Econ 1995;14:171-89.

15 Brooks R. EuroQol: the current state of play. Health Policy 1996;37:53-72.

16 Dolan P. Modeling valuations for EuroQol health states. Med Care 1997;35:1095-108.

17 Shaw JW, Johnson JA, Coons SJ. US valuation of the EQ-5D health states: development and testing of the D1 valuation model. Med Care 2005;43:203-20.

18 Willan AR, Briggs $A H$, Hoch JS. Regression methods for covariate adjustment and subgroup analysis for non-censored cost-effectiveness data. Health Econ 2004; 13:461-75.

19 Thompson SG, Barber JA. How should cost data in pragmatic randomised trials be analysed? BMJ 2000;320:1197-200.

20 van Hout BA, Al MJ, Gordon GS, et al. Costs, effects and C/E-ratios alongside a clinical trial. Health Econ 1994;3:309-19.

21 NICE. Methods for the development of NICE public health guidance. 3rd edn. 2012. [cited 2013 April 3]. http://publications.nice.org.uk/ methods-for-the-development-of-nice-public-health-guidance-third-edition-pmg4

22 Shiroiwa T, Sung YK, Fukuda T, et al. International survey on willingness-to-pay (WTP) for one additional QALY gained: what is the threshold of cost effectiveness? Health Econ 2010;19:422-37.

23 van den Hout WB, Goekoop-Ruiterman YP, Allaart CF, et al. Cost-utility analysis of treatment strategies in patients with recent-onset rheumatoid arthritis. Arthritis Rheum 2009;61:291-9.

24 van den Hout W, Klarenbeek N, Dirven L, et al. Long-term cost-utility analysis of treatment strategies in patients with recent-onset rheumatoid arthritis- 5 year follow-up data from the BeSt study. Ann Rheum Dis 2012;71(Suppl3):363.

25 Boers M. The cost-utility analysis of the BeSt trial: is a camel in fact a horse with abnormalities in the distribution of dorsal fat? Comment on the article by van den Hout et al. Arthritis Rheum 2009;61:1616-17; author reply 1617-1618.

26 Chen YF, Jobanputra $\mathrm{P}$, Barton $\mathrm{P}$, et al. A systematic review of the effectiveness of adalimumab, etanercept and infliximab for the treatment of rheumatoid arthritis in adults and an economic evaluation of their cost-effectiveness. Health Technol Assess 2006;10:iii-iv, xi-xiii, 1-229. 
27 Moreland LW, O'Dell JR, Paulus HE, et al. A randomized comparative effectiveness study of oral triple therapy versus etanercept plus methotrexate in early aggressive rheumatoid arthritis: the treatment of Early Aggressive Rheumatoid Arthritis Trial. Arthritis Rheum 2012;64:2824-35.

28 Rantalaiho V, Kautiainen $\mathrm{H}$, Korpela $\mathrm{M}$, et al. Targeted treatment with a combination of traditional DMARDs produces excellent clinical and radiographic long-term outcomes in early rheumatoid arthritis regardless of initial infliximab. The 5-year follow-up results of a randomised clinical trial, the NEO-RACo trial. Ann Rheum Dis 2014;73:1954-61.

29 O'Dell JR, Mikuls TR, Taylor TH, et al. Therapies for active rheumatoid arthritis after methotrexate failure. N Engl J Med 2013;369:307-18.

30 Jacobsson LT, Lindroth Y, Marsal L, et al. Rheumatoid arthritis: what does it cost and what factors are driving those costs? Results of a survey in a communityderived population in Malmo, Sweden. Scand I Rheumatol 2007;36:179-83. 